\title{
Palliative Care: Challenges for the Health Systems
}

\author{
Regina Aparecida Garcia de Lima
}

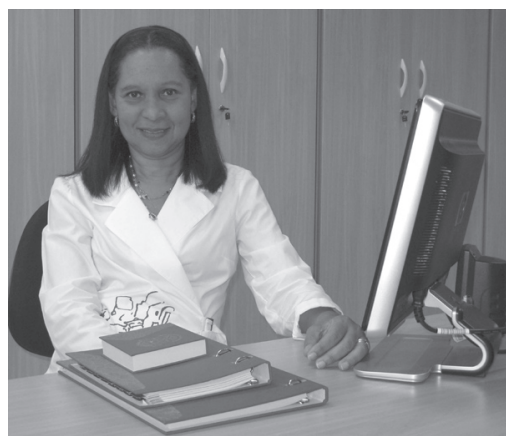

Reflections on the development of technologies in the health area have been accompanied by issues related to the finiteness and quality of life, because if technology can provide a cure for an illness, it can also prolong life, often without considering its quality. Thus, technologies for interventions in chronic-degenerative disease processes can transform the final phase of life into a long and painful process of dying(1) a moment in which patients and their families need a healthcare approach which focuses on the quality of life and of death.

Palliative care is constituted in a modality of healthcare that meets this reality to minimize the suffering caused by the diseases and by the technological interventions. According to the World Health Organization, palliative care consists of measures that improve the quality of life of patients facing a terminal illness and their families by preventing and relieving suffering through early identification, correct evaluation and treatment of the pain and other physical, psychosocial and spiritual problems ${ }^{(2)}$.

A World Health Organization document entitled Better palliative care for older people ${ }^{(3)}$, reaffirms and justifies the need to include palliative care as part of the integral healthcare, in all chronic diseases and especially in the elderly care programs. In this document, the education of the teams and of the general population is emphasized regarding the principles and benefits of palliative care.

Studies on global estimates of palliative care treatment have identified that 115 countries maintain one or more palliative care services and that $60 \%$ of the 56 million people who die each year have benefited from some form of palliative care. Although there is a worldwide expansion of this care modality, we are still faced with more than 20 million people dying without access to care that seeks to alleviate the suffering and the disease symptoms, to preserve the autonomy of the patient and their right of participation, and to provide a better quality of life(4).

The finding that a large number of people still do not receive adequate care in their death process makes us think about the need to expand the coverage of these services. This is not the only challenge for the health systems, since the production of this care has as its basis human and scientific competence. In this sense, the production and dissemination of knowledge on this thematic is vital for the elaboration of the best practices in palliative care.

\section{References}

1. Rabello CAFG, Rodrigues PHA. Saúde da Família e cuidados paliativos infantis: ouvindo os familiares de crianças dependentes de tecnologia. Ciênc Saúde Col. 2010;15(2):379-88. 
2. World Health Organization. Cancer pain relief and palliative care. Geneva: World Health Organization; 2002.

3. World Health Organization. Better palliative care for older people. Geneva: World Health Organization; 2004.

4. Wright M, Wood J, Lynch, Clark D. Mapping levels of palliative care development: a global view. Pain Sympton Manage. 2008;35(5): 469-85.

Regina Aparecida Garcia de Lima is Scientific Editor of the Latin American Journal of Nursing, and Full Professor of the University of São Paulo at Ribeirão Preto College of Nursing, WHO Collaborating Centre for Nursing Research Development, Brazil, e-mail: limare@usp.br. 